\title{
Research on the Economic Development of Real Estate in Guangdong-Hong Kong-Macao Greater Bay Area
}

\author{
Tingting Qi \\ School of Economics, Jinan University, Guangzhou, China \\ Email: lqitingting@163.com
}

How to cite this paper: Qi, T. T. (2020). Research on the Economic Development of Real Estate in Guangdong-Hong Kong-Macao Greater Bay Area. American Journal of Industrial and Business Management, 10, 1707-1724.

https://doi.org/10.4236/ajibm.2020.1010107

Received: September 30, 2020

Accepted: October 26, 2020

Published: October 29, 2020

Copyright $\odot 2020$ by author(s) and Scientific Research Publishing Inc. This work is licensed under the Creative Commons Attribution International License (CC BY 4.0).

http://creativecommons.org/licenses/by/4.0/

\begin{abstract}
The construction of the Guangdong-Hong Kong-Macao Greater Bay Area has injected vitality into the new development of China's economy and has also created greater vitality for China's implementation of the "One Belt, One Road" strategy and the "two hundred years" goal. The economic development of the Guangdong-Hong Kong-Macao Greater Bay Area has received extensive attention from domestic scholars. As one of the pillar industries of national economic development, real estate economic development has also received great attention in the development of various industries in the Guangdong-Hong Kong-Macao Greater Bay Area. The development of the real estate economy in the Greater Bay Area of Guangdong, Hong Kong and Macao and its current opportunities and challenges require serious attention and analysis by scholars. Because the development of it has risen to the national strategic level, its development is of great significance to the whole country. Therefore, based on the analysis of the development status of the real estate economy, and the corresponding solutions, this paper has important theoretical significance and realistic meaning for the real estate economic development of Guangdong-Hong Kong-Macao Greater Bay Area.
\end{abstract}

\section{Keywords}

Guangdong-Hong Kong-Macao Greater Bay Area, Bay Area Economy, Real Estate

\section{Introduction}

\subsection{Background of Topic Selection}

The report of the 19th National Congress of the Communist Party of China 
pointed out that "China should take urban agglomeration as the main body to construct the urban pattern of coordinated development of large, medium and small cities and small towns". "China is focusing on the construction of the Guangdong-Hong Kong-Macao Greater Bay Area, and comprehensively promotes mutually beneficial cooperation between the mainland and Hong Kong and Macao". On July 1, 2017, representatives of relevant cities of Guangdong, Hong Kong and Macao signed the framework agreement in Hong Kong, which pointed out that the Guangdong-Hong Kong-Macao Greater Bay Area should be built into a world-class Bay area after Tokyo, New York and Los Angeles.

The construction of Guangdong-Hong Kong-Macao Bay area has injected vitality into the new development of China's economy. China's one belt, one road strategy and the "two one hundred year" goals will also create greater vitality for China. The construction of the strategy initiative, Guangdong Province, Hong Kong and Macao, should be based on the strategic plan of "one belt and one road", and the construction of the bay area of Guangdong, Hong Kong and Macau into a demonstration area for China's opening up.

The Pearl River Delta urban agglomerations, with the preferential policies of the national pilot zone of reform and opening up, as the inland hinterland of Guangdong-Hong Kong-Macao Greater Bay Area and the location adjacent to Hong Kong and Macao, have many geographical advantages and high-tech advantages. Harvard University professor Michael (2002) mentioned in his masterpiece "National Competitive Advantage" that technological innovation has become the main factor of national competitiveness. On September 27, 2016, the main bridge of Hong Kong-Zhuhai-Macao Bridge, the longest sea crossing bridge in the world, was officially opened. The space-time compression effect of the Hong Kong-Zhuhai-Macao Bridge is more conducive to improving the traffic convenience of cities in the Pearl River Delta and Hong Kong to Macao. Promote the interaction among the three regions and the development of regional economic integration. The completion of the Hong Kong-Zhuhai-Macao Bridge will further improve the traffic in the bay area, further facilitate the residents' life, service and cultural exchanges, and greatly promote the overall economic vitality of the bay area. The vitality of economic development and the flow of personnel in the bay area also bring new demands for the development of real estate agents in the bay area. In the past 40 years of reform and opening up, with the deepening of reform and opening up, the real estate market of 9 inland cities in Guangdong, Hong Kong, Macao district has also been greatly developed, and the house prices are also rising. DTZ (2018) analyzes within the Guangdong-Hong Kong-Macao Bay area, various cities and regions need to make full use of their advantages to strengthen exchanges, cooperation and integrated development in the bay area, seize the development opportunities of the three major industries, seize the opportunities, and achieve common economic development.

Under the background of these developments, this paper mainly studies and analyzes the development status of the real estate industry in the Guang- 
dong-Hong Kong-Macao Bay area, the current situation of the development of the real estate industry in the bay area, the development gap between the inland cities in the bay area, and the development gap among the cities in the bay area, and the existing problems in the development process.

\subsection{Significance of Research}

According to the statistical results, in 2017, the population of Guangdong-Hong Kong-Macao Greater Bay Area Urban Agglomeration exceeded 60 million, and the GDP reached 10,059.4 billion yuan (Data source: Statistics Bureau of Guangdong Province, Hong Kong Statistics Department, Macao Statistics Bureau). It has developed into a new economic highland, which will also provide opportunities for investment in real estate development. With China's "The belt and road initiative" development strategy advancing in recent years, Under the good planning of the big bay area of the Guangdong-Hong Kong-Macao Greater Bay Area, which has many unique advantages, has been developing to the world-class Bay area city group, attracting the real estate enterprises to frequent in the big bay area. In the process of deepening the reform and opening up, the bay area has been developing continuously. Then, how the real estate industry in the bay area has experienced developments? What is the current state of development? The comparative analysis of the real estate development of various cities in the bay area, as well as the discussion and research on the problems, opportunities and challenges existing in the development of the real estate industry in the bay area is of great theoretical and practical significance. Wang (2018) thought that the real estate industry insiders believe that: Guangdong-Hong Kong-Macao Greater Bay Area has created more opportunities for the development of real estate enterprises. In addition to Guangzhou and Shenzhen, Dongguan, Foshan, Zhuhai and other cities have good development potential based on the in-depth development of Guangdong, Hong Kong and Macao.

The purpose of this study is to divide the real estate development status of each city, analyze the gap of real estate development in each city and the current development situation through the research on the current real estate development situation. At the same time, it is also the key to enhance the competitiveness and comprehensive strength of the Guangdong-Hong Kong-Macao Greater Bay Area.

The significance of this paper is mainly divided into two aspects: the first one is to improve the value of land use on the basis of promoting the intensive use of land resources in bay area district. Because China's economic development is in a period of transformation and the industry is constantly upgrading, focusing on the development of real estate in the bay area is conducive to the realization of intensive land development on the basis of limited land resources, and at the same time, it can promote the sustainable development of the real estate industry in the bay area; The second one is to help real estate enterprises improve their awareness and competitiveness, In the face of the increasingly serious polarization of the real estate industry, the real estate enterprises that have entered 
the bay area or have not yet entered the bay area should pay more attention to the new economic growth nodes of the real estate economic development in the bay area, grasp the real estate development situation in the bay area, and seek strategies and development in the economic environment.

\section{Research Method}

At present, there are three major Bay areas in the world (New York Bay area ${ }^{1}$, San Francisco Bay Area ${ }^{2}$ in the United States and Tokyo Bay in Japan ${ }^{3}$ ). With their superior geographical location as the carrier, based on the complete high-level education alliance, they have constructed a complete set of innovation system, and thus formed their own high-level development clusters with their own characteristics. According to the statistics of the world bank, more than $60 \%$ of the world's economy is concentrated in the bay area. The reason why these three Bay areas have developed so fast is that they have common characteristics in the process of development. Wang (2017) focused on its following advantages: 1) excellent location; 2) the tertiary industry is prominent, and the value industry is developing significantly; 3) the regional innovation system is perfect; 4) the transportation is convenient and suitable for living and working; 5) the industrial division system guided by the situation. Then, what are the development advantages and development status of Guangdong-Hong Kong-Macao Greater Bay Area, which need extensive attention and research by scholars.

The research method of this paper is to carefully sort out and analyze the existing literature, and combine with the method of econometrics to analyze the current situation of real estate economic development in Guangdong-Hong Kong-Macao Greater Bay Area, and put forward corresponding solutions, which is of great significance to the development of real estate economy in Guangdong-Hong Kong-Macao Greater Bay Area.

\section{Research Contents}

The first chapter is the introduction, which mainly expounds the research background, significance and research methods; the second chapter is the research methods. This paper mainly uses the literature analysis and quantitative analysis to make a more rigorous and comprehensive discussion on the research content; The third chapter introduces the research content; the fourth chapter analyzes the development of real estate industry in Guangdong-Hong Kong-Macao Greater Bay Area; The fifth chapter is the measurement and specific analysis of the real estate development gap of each city in the bay area. Through principal component analysis and cluster analysis, the paper analyzes the real estate development status of each city in the bay area; The main content of the sixth

${ }^{1}$ New York Bay area with a total area of 33,484 square kilometers (CSA statistical caliber in 2015), has become a metropolitan area covering 31 counties in New York.

${ }^{2}$ The San Francisco Bay Area, popularly referred to as the Bay Area or simply the Bay, is a populous region surrounding the San Francisco, San Pablo, and Suisun Bay estuaries in Northern California.

${ }^{3}$ Tokyo Bay is a bay located in the southern Kantō region of Japan, and spans the coasts of Tokyo, Kanagawa Prefecture, and Chiba Prefecture. 
chapter is based on the fourth and fifth chapters of the real estate development situation and development gap analysis, and found the problems and opportunities: opportunities and challenges; The seventh chapter puts forward countermeasures and suggestions for the development of real estate in district: First, it is necessary to improve the level of real estate development in the bay area and pay attention to the development of high-quality direction; Second, the bay area should meet the needs of urban development with different levels of development, and actively play the role of real estate enterprises in the bay area; Third, the bay area is to improve the housing and high value-added real estate construction in the bay area, gather management personnel, and provide a higher level of basic support for the comprehensive development of Guangdong-Hong Kong-Macao Greater Bay Area.

\section{Analysis of Real Estate Development in Bay Area}

\subsection{Analysis of Real Estate Development in the Bay Area of China}

Table 1 shows that in the data of 2017, the sales area of commercial housing in the Pearl River Delta region decreased by $2.3 \%$ year-on-year, and the investment amount increased by $14.3 \%$; The sales area in Shantou, Chaozhou, Jieyang and Shanwei (these cities named East wing area) increased by $58.1 \%$ and the investment increased by $30.4 \%$ year on year; The sales area and investment amount in Zhangjiang, Maoming and Yangjiang (these cities named Wast wing area) increased by $50.1 \%$ and $45.2 \%$ respectively; In the data from January to November 2018, the sales area of the Pearl River Delta region decreased by $14.1 \%$ year-on-year, and the investment amount increased by $16.3 \%$; the sales area and investment amount in those regions decreased by $5.9 \%$ and increased by $41.1 \%$ respectively; the sales area Shaoguan, Meizhou, Qingyuan, Heyuan and Yunfu (these cities named Mountainous area)decreased by $11.5 \%$, and the investment amount increased by $21.4 \%$.

Deng (2017) pointed that with the rapid development of urbanization in the Pearl River Delta, its industrial agglomeration is strong. It can be seen from Table 1 that in 2017, the sales area of the Pearl River Delta region was 104.447 million

Table 1. Sales of commercial housing by region in Guangdong.

\begin{tabular}{cccc}
\hline Time & Region & $\begin{array}{c}\text { the sales area } \\
\text { (year-on-year) }\end{array}$ & $\begin{array}{c}\text { investment amount } \\
\text { (year-on-year) }\end{array}$ \\
\hline From Jan. to & East \& West wing area & $-5.90 \%$ & $41.10 \%$ \\
Nov. in 2018 & Mountainous area & $-11.50 \%$ & $21.40 \%$ \\
& Pearl River Delta & $-14.10 \%$ & $16.30 \%$ \\
\hline \multirow{2}{*}{2017} & East wing area & $58.10 \%$ & $30.40 \%$ \\
& West wing area & $50.10 \%$ & $45.20 \%$ \\
& Mountainous area & $29.70 \%$ & $25.20 \%$ \\
& Pearl River Delta & $-2.30 \%$ & $14.30 \%$ \\
\hline
\end{tabular}

Source: Guangdong Provincial Bureau of Statistics. 
square meters, a year-on-year decrease of $2.3 \%$. However, the sales area and sales volume still accounted for a very high proportion of the province, $65.4 \%$ and 81.3\% respectively. The amount of investment in the Pearl River Delta region increased by $14.3 \%$ year-on-year, down by 1.3 percentage points. From January to November of 2018, the decline rate of commercial housing sales area in the Pearl River Delta region was reduced. Therefore, the Pearl River Delta region is the core area of Guangdong real estate market.

From Table 2 and the development of the market, in the Guangdong-Hong Kong-Macao Bay area, the total GDP exceeded 10 trillion yuan in 2017 and 10.6 trillion yuan in 2018. The Guangdong-Hong Kong-Macao Bay area is becoming a new highland of global economic development and the world's most dynamic and innovation gathering economic development area, which also provides great opportunities for the development of the real estate economy. According to statistics, the urban agglomeration population of Guangdong, Hong Kong, Macao and bay area exceeds 60 million. According to Table 2, the GDP in 2018 exceeded 10.6 trillion yuan. Such a new highland of economic development, the emergence of a huge urban agglomeration with great vitality and innovation will surely lead to a substantial increase in real estate investment. Therefore, in recent years, various real estate enterprises have frequently settled in Guangdong, Hong Kong and Macao. According to CRIC statistical data monitoring, the major real estate enterprises have added a lot of land reserves in the bay area. From 2017 to April 2018, Vanke added a large number of land reserves in the bay area, about 13.16 million square meters; Evergrande added 8.46 million square meters of land reserves. In addition to non-Guangdong local enterprises are also

Table 2. GDP and growth rate of Guangdong-Hong Kong-Macao Bay area cities in 2017 and 2018 .

\begin{tabular}{ccccc}
\hline Region & $\begin{array}{c}\text { GDP in 2017 } \\
\text { (Billion) }\end{array}$ & $\begin{array}{c}\text { GDP growth } \\
\text { rate in 2017 }\end{array}$ & $\begin{array}{c}\text { GDP in 2018 } \\
\text { (Billion) }\end{array}$ & $\begin{array}{c}\text { GDP growth } \\
\text { rate in 2018 }\end{array}$ \\
\hline Hong Kong & 23,049 & $3.80 \%$ & & \\
Macao & 31,102 & $10.90 \%$ & $24,221.98$ & $7.60 \%$ \\
Shenzhen & $22,438.39$ & $8.80 \%$ & $22,859.35$ & $6 \%$ \\
Guangzhou & $21,503.15$ & $7 \%$ & & $7.40 \%$ \\
Foshan & 9500 & $8.60 \%$ & 8378.59 & $6 \%$ \\
Dongguan & 7582.12 & $8.10 \%$ & 4103.05 & $5.90 \%$ \\
Huizhou & 3830.58 & $7.60 \%$ & 3632.7 & $7.80 \%$ \\
Zhongshan & 3450.31 & $6.60 \%$ & 2900.41 & \\
Jiangmen & 2690.25 & $8.10 \%$ & & $6.60 \%$ \\
Zhuhai & 2564.73 & $9.20 \%$ & 2201.8 & \\
Zhaoqing & 2200.61 & $5.20 \%$ & & \\
\hline
\end{tabular}

Source: Statistics Bureau of Guangdong Province, Hong Kong Statistics Department, Macao Statistics Bureau. 
Guangdong local real estate enterprises actively investing in the bay area, some actively competing. For example, according to the data of China real estate news, the bay area is in a period of upsurge: Taihe Group, Rongxin group and Yuzhou group. Under the background of national economic development and based on the development prospect of the bay area, the real estate enterprises far away from the bay area have also begun to actively layout in Guangzhou, Shenzhen and other places. The representative real estate enterprises include green city and Rongchuang.

At present, the economic development of Hong Kong, Macao, Shenzhen and Guangzhou is mature, and the real estate market is developing rapidly and gradually becoming mature; Foshan, Dongguan, Huizhou, Zhuhai and Zhongshan have benefited from the development spillover of Guangzhou, Shenzhen, Hong Kong and Macao, and the real estate market in Jiangmen and Zhaoqing is still in the stage of development and development, with development potential Larger.

\subsection{Index Selection of Quantitative Analysis}

The development process and degree of real estate in different cities in the bay area are different, and the development of real estate economy is not only related to the economic indicators of real estate, but also related to other related economic development. The real estate development of cities in Guangdong Province is later than that of Hong Kong and Macao. Peng (2018) also pointed that due to the different administrative system and legal system under the "one country, two systems" policy, it is difficult to unify the different economic indicators within the Guangdong Hong Kong Macao Bay Area (Guangdong cities and Hong Kong and Macao), and there are some differences in statistical indicators. It usually needs to be calculated to get a unified index for analysis. Moreover, it is difficult to unify the indicators when the level of economic development and social and political factors are different. There are also three areas in a region lack of one of the data and cannot be unified analysis, this paper can only give up this indicator, looking for other related indicators. Therefore, this paper in the process of index selection, try to choose the representative index with the smallest error. Generally speaking, according to the principle of feasibility and purpose of the indicators, the following indicators are found as the analysis data of this paper:

1) Indicators that can represent the level of economic development of each region: per capita GDP, per capita income and average wages of urban workers in each city in the bay area. First of all, the per capita GDP (X1) of each city can reflect the economic capacity of a region's citizens, while the per capita income (X2) and the average wage (X3) of urban workers can reflect the purchasing power of employees in the region;

2) People's living standard index: Residents' consumption index (X4), which can directly reflect the price level changes of household consumption goods or services, is closely related to people's lives, and also plays an important role in 
the process of economic development;

3) Indicators of land resources in various regions: population density index (x5), which reflects the limited social and natural resources, more or less land resources will affect the price of land, which will further affect the living environment of residents. This can also explain why in cities with high population density, the prices of buildings are generally relatively high.

4) The real estate investment situation of each region: the investment amount of real estate development completed by each city (X6), the investment amount of fixed assets (X7), the real estate and fixed investment of residents can reflect their confidence in the prospect of real estate related economic development and development;

5) Land construction of commercial housing in various regions: newly developed area (X8) and completed area (X9). The newly developed housing area reflects the market demand, while the completed commercial housing area reflects the market demand in the early stage of the real estate market.

\section{The Method of Dividing the Real Estate Development Status in the Bay Area}

In this report, in order to study the real estate development status of each city in Guangdong-Hong Kong-Macao Greater Bay Area more clearly, so as to more accurately locate the measures that should be taken in the development process of each city, the principal component analysis method and cluster analysis method are used in this paper.

The essence of principal component analysis (PCA) is to transform many indexes into several principal components (i.e. comprehensive indicators) by dimension reduction. This analysis method uses less variables to explain most of the variables in the data, and then conducts cluster analysis again according to the principal component analysis method. Cluster analysis is to divide the research objects into relatively homogeneous groups for statistical analysis. Principal component analysis and cluster analysis are used to analyze and divide. First of all, in Chapter 3, we discussed the quantitative index data selected according to the principle of feasibility and purpose. Wei (2006) proposed the measurement of real estate market development difference between Hong Kong, Macao and Guangdong, the statistical data of 9 cities in Guangdong-Hong Kong-Macao Greater Bay Area in 2017 are as follows (showing in Table 3):

X1: per capita GDP of each city (yuan);

$\mathrm{X} 2$ : per capita resident income (yuan);

$\mathrm{X} 3$ : average wage of urban workers (yuan);

$\mathrm{X} 4$ : resident consumption index;

$\mathrm{X} 5$ : population density index (person $\left./ \mathrm{km}^{2}\right)$;

X6: completed investment in real estate development (10,000 yuan);

X7: fixed assets investment (million yuan);

X8: newly developed housing area (10,000 square meters);

$\mathrm{X} 9$ : completed building area (10,000 square meters). 
Table 3. Cities in Guangdong-Hong Kong-Macao bay area in 2017.

\begin{tabular}{|c|c|c|c|c|c|}
\hline & $\mathrm{X} 1$ & $\mathrm{X} 2$ & $\mathrm{X} 3$ & $\mathrm{X} 4$ & $\mathrm{X} 5$ \\
\hline Hong Kong & $295,196.72$ & $333,729.53$ & $123,994.8$ & 104.5 & 6830 \\
\hline Macao & $516,926.49$ & $4,426,461.47$ & 149,400 & 109.56 & 21,400 \\
\hline Guangzhou & 150,678 & 55,400 & $91,515.55$ & 102.3 & 2000 \\
\hline Shenzhen & 183,544 & 52,938 & $97,267.88$ & 101.4 & 6272 \\
\hline Zhuhai & 155,502 & $46,826.4$ & $76,033.67$ & 100.8 & 1017 \\
\hline Zhongshan & 105,711 & $36,608.3$ & 67,728 & 101.6 & 1828 \\
\hline Foshan & 124,324 & $46,848.5$ & $69,735.6$ & 101.9 & 2016 \\
\hline Huizhou & 80,205 & $36,608.3$ & $60,872.6$ & 101.8 & 421 \\
\hline Dongguan & 91,329 & $46,739.1$ & 57,649 & 101.4 & 3391 \\
\hline Jiangmen & 59,089 & $32,477.8$ & 66,107 & 101.6 & 480 \\
\hline Zhaoqing & 51,464 & $28,276.1$ & $60,283.75$ & 101.6 & 276 \\
\hline X6 & & $\mathrm{X} 7$ & $\mathrm{X} 8$ & & X9 \\
\hline $22,242,791$ & & $517,106.02$ & 137.7 & & 856.2 \\
\hline $15,974,857.1$ & & $61,329.44$ & 41.09 & & 83.96 \\
\hline $27,028,935$ & & 591,983 & 5320.11 & & $19,323.31$ \\
\hline $21,308,620$ & & 514,732 & 3141.98 & & 9240.74 \\
\hline $6,661,158$ & & 166,202 & 681.01 & & 1957.27 \\
\hline $6,239,748$ & & 124,848 & 207.17 & & 500.92 \\
\hline $14,539,898$ & & 426,579 & 1526.92 & & 3225.98 \\
\hline $8,841,949$ & & 223,488 & 379.57 & & 1274.14 \\
\hline $7,021,544$ & & 171,283 & 305.67 & & 946.91 \\
\hline $4,505,563$ & & 177,483 & 760.05 & & 2516.28 \\
\hline $2,080,393$ & & 149,755 & 284.74 & & 539.77 \\
\hline
\end{tabular}

Source: Statistics Bureau of Guangdong Province, Hong Kong Statistics department, Macao Statistics Bureau.

\subsection{Principal Component Analysis}

According to the principal component analysis method and processed by software, we can get the following result index composition matrix table, principal component factor load coefficient table, principal component factor eigenvalue, contribution rate and cumulative contribution rate table, and the principal component gravel diagram is shown below (showing in Tables 4-6 and Figure 1).

Generally speaking, the component whose eigenvalue is greater than 1 is selected as the principal component. Through principal component analysis, it can be seen from Table 6 that the eigenvalues of components 1 and 2 are greater than 1, which can explain $92.369 \%$ variance, it is enough to represent all the information represented by the original factors. According to the principle that the 


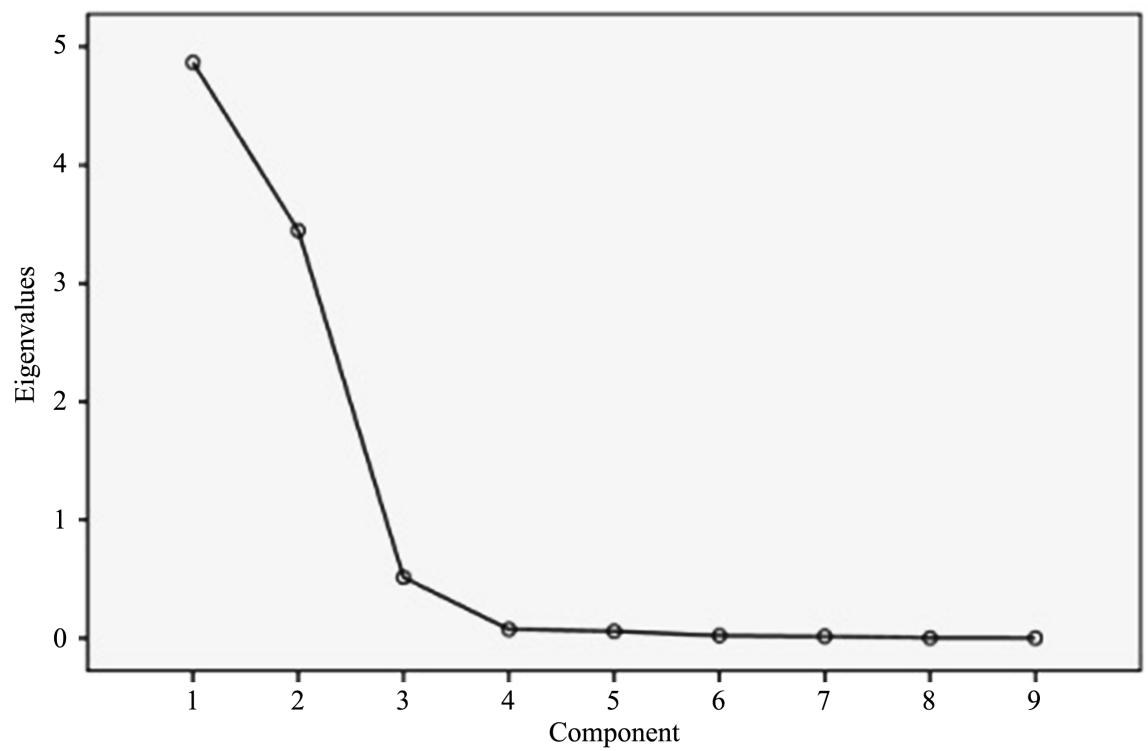

Figure 1. Scree plot.

Table 4. Correlation matrix.

\begin{tabular}{|c|c|c|c|c|c|c|c|c|c|}
\hline & $\mathrm{X} 1$ & $\mathrm{X} 2$ & $\mathrm{X} 3$ & $\mathrm{X} 4$ & $\mathrm{X} 5$ & X6 & $\mathrm{X} 7$ & $\mathrm{X} 8$ & X9 \\
\hline $\mathrm{X} 1$ & 1.000 & 0.889 & 0.960 & 0.934 & 0.956 & 0.492 & -0.013 & -0.104 & -0.082 \\
\hline $\mathrm{X} 2$ & 0.889 & 1.000 & 0.772 & 0.947 & 0.946 & 0.174 & -0.361 & -0.236 & -0.214 \\
\hline $\mathrm{X} 3$ & 0.960 & 0.772 & 1.000 & 0.873 & 0.884 & 0.644 & 0.198 & 0.054 & 0.081 \\
\hline $\mathrm{X} 4$ & 0.934 & 0.947 & 0.873 & 1.000 & 0.940 & 0.343 & -0.165 & -0.216 & -0.178 \\
\hline X5 & 0.956 & 0.946 & 0.884 & 0.940 & 1.000 & 0.372 & -0.149 & -0.153 & -0.141 \\
\hline X6 & 0.492 & 0.174 & 0.644 & 0.343 & 0.372 & 1.000 & 0.833 & 0.684 & 0.690 \\
\hline X7 & -0.013 & -0.361 & 0.198 & -0.165 & -0.149 & 0.833 & 1.000 & 0.744 & 0.722 \\
\hline $\mathrm{X} 8$ & -0.104 & -0.236 & 0.054 & -0.216 & -0.153 & 0.684 & 0.744 & 1.000 & 0.989 \\
\hline X9 & -0.082 & -0.214 & 0.081 & -0.178 & -0.141 & 0.690 & 0.722 & 0.989 & 1.000 \\
\hline
\end{tabular}

Table 5. Common factor variance.

\begin{tabular}{lll}
\hline & Initial & Square \\
\hline X1 & 1.000 & 0.978 \\
X2 & 1.000 & 0.920 \\
X3 & 1.000 & 0.943 \\
X4 & 1.000 & 0.956 \\
X5 & 1.000 & 0.962 \\
X6 & 1.000 & 0.949 \\
X7 & 1.000 & 0.844 \\
X8 & 1.000 & 0.889 \\
X9 & 1.000 & 0.874
\end{tabular}

Method: Principal component analysis. 
Table 6. Explained total variance.

\begin{tabular}{ccccccc}
\hline \multirow{2}{*}{ Ingredients } & \multicolumn{3}{c}{ Initial eigenvalue } & \multicolumn{3}{c}{ Extract Square sum load } \\
\cline { 2 - 7 } & Total & variance & cumulative \% & Total & variance & cumulative \% \\
\hline 1 & 4.867 & 54.079 & 54.079 & 4.867 & 54.079 & 54.079 \\
2 & 3.446 & 38.291 & 92.369 & 3.446 & 38.291 & 92.369 \\
3 & 0.514 & 5.714 & 98.083 & & & \\
4 & 0.074 & 0.827 & 98.910 & & & \\
5 & 0.058 & 0.649 & 99.560 & & & \\
6 & 0.022 & 0.244 & 99.804 & & & \\
7 & 0.015 & 0.167 & 99.971 & & & \\
8 & 0.002 & 0.021 & 99.992 & & & \\
9 & 0.001 & 0.008 & 100.000 & & & \\
\hline
\end{tabular}

Extraction method: Principal component analysis.

\begin{tabular}{lcc}
\hline \multicolumn{2}{c}{ Composition Matrix A } \\
\cline { 2 - 3 } & \multicolumn{2}{c}{ Composition Matrix } \\
\hline X1 & 0.988 & 2 \\
\hline X2 & 0.932 & 0.037 \\
X3 & 0.943 & -0.227 \\
X4 & 0.972 & 0.232 \\
X5 & 0.978 & -0.109 \\
X6 & 0.453 & -0.069 \\
X7 & -0.065 & 0.862 \\
X8 & -0.120 & 0.916 \\
X9 & -0.095 & 0.935 \\
\hline
\end{tabular}

Extraction method: Principal component analysis. a. Two ingredients have been extracted.

cumulative contribution rate is greater than or equal to $85 \%$, the first two principal factors are extracted as the analysis indicators of regional economic development in Guangdong, Hong Kong and Macao. From the factor load analysis, the first main factor is mainly composed of variables X1: per capita GDP (yuan), X2: per capita income (yuan), X3: average wage of urban workers (yuan), X4: resident consumption index, X5: population density index (person $/ \mathrm{km}^{2}$ ), which is called the first main factor of economic aggregate. The second main factor is mainly composed of X6: real estate development completed investment $(10,000$ yuan), X7: fixed assets investment (million yuan), X8: newly developed housing area (10,000 square meters), $x 9$ : completed housing area (10,000 square meters), which can be called economic development factor.

According to the above analysis, the comprehensive evaluation value of the real estate economic development level in Guangdong-Hong Kong-Macao Greater Bay Area can be expressed as Table 7. 
Table 7. Scores and rankings by factors.

\begin{tabular}{ccccc}
\hline Group Name & Score 1 & Ranking 1 & Score 2 & Ranking 2 \\
\hline Hong Kong & 9.35 & 1 & -4.07 & 14 \\
Macao & 1.27 & 4 & -3.67 & 13 \\
Guangzhou & 3.87 & 2 & 5.03 & 1 \\
Shenzhen & 3.55 & 3 & 4.7 & 2 \\
Zhuhai & -0.445 & 7 & -0.0639 & 7 \\
Zhongshan & -0.567 & 8 & 0.669 & 4 \\
Foshan & 0.391 & 6 & 0.624 & 5 \\
Huizhou & -0.955 & 10 & -0.107 & 11 \\
Dongguan & 0.604 & 5 & 1.15 & 3 \\
Jiangmen & -0.64 & 9 & 0.365 & 6 \\
Zhaoqing & -1.21 & 11 & -0.129 & 12 \\
\hline
\end{tabular}

According to the factor scores and ranking in Table 7, in the first type of principal component factor analysis, Hong Kong, Guangzhou, Shenzhen, Macao, Dongguan and Foshan are the top cities in the score, among which Hong Kong is significantly higher than other cities in the bay area. Therefore, the real estate investment and housing purchasing power of Hong Kong are the highest in the bay area, and in the second category In the principal component factor analysis, Guangzhou, Shenzhen and Dongguan scored the highest, but Hong Kong and Macao, the regions with rapid economic development, ranked in the last two places. In fact, because the land area of Hong Kong and Macao is very small, the land area to be developed and utilized is small.

\subsection{Cluster Analysis}

According to the results of cluster analysis (showing in Table 8 and Table 9), the economic development level of real estate in Guangdong-Hong Kong-Macao Greater Bay Area can be roughly divided into five categories: the first is Hong Kong; the second is Macao; the third is Guangzhou and Shenzhen; the fourth is Zhuhai, Foshan, Dongguan, Zhongshan and Jiangmen; the fifth is Huizhou and Zhaoqing.

\section{Development Prospect of Real Estate in Guangdong, Hong Kong and Macao}

\subsection{Existing Problems}

\subsubsection{Due to Different Market Development, the Comprehensive Strength of Real Estate Enterprises in the Bay Area Is Required to Be Higher}

According to the previous data analysis, from the perspective of market development, the real estate markets in Hong Kong and Macao started early and developed rapidly, with high maturity. The economic development of Guangzhou 
Table 8. Clustering table.

\begin{tabular}{|c|c|c|c|c|c|c|}
\hline \multirow{2}{*}{ Order } & \multicolumn{2}{|c|}{ The clustering combination } & \multirow{2}{*}{ Coefficient } & \multicolumn{2}{|c|}{ First order cluster } & \multirow{2}{*}{$\begin{array}{l}\text { Next } \\
\text { order }\end{array}$} \\
\hline & Cluster1 & Cluster 2 & & Cluster 1 & Cluster 2 & \\
\hline 1 & 5 & 9 & $1.344 \mathrm{E} 11$ & 0 & 0 & 2 \\
\hline 2 & 5 & 6 & 3.979E11 & 1 & 0 & 4 \\
\hline 3 & 1 & 4 & $9.648 \mathrm{E} 11$ & 0 & 0 & 8 \\
\hline 4 & 5 & 10 & $4.667 \mathrm{E} 12$ & 2 & 0 & 5 \\
\hline 5 & 5 & 8 & $8.418 \mathrm{E} 12$ & 4 & 0 & 7 \\
\hline 6 & 2 & 7 & $2.153 \mathrm{E} 13$ & 0 & 0 & 9 \\
\hline 7 & 5 & 11 & $2.286 \mathrm{E} 13$ & 5 & 0 & 10 \\
\hline 8 & 1 & 3 & $2.787 \mathrm{E} 13$ & 3 & 0 & 9 \\
\hline 9 & 1 & 2 & $8.453 \mathrm{E} 13$ & 8 & 6 & 10 \\
\hline 10 & 1 & 5 & $2.342 \mathrm{E} 14$ & 9 & 7 & 0 \\
\hline
\end{tabular}

Table 9. Classification results after cluster analysis.

\begin{tabular}{cccccc}
\hline Classification & & & & \\
\hline Class 1 & Hong kong & & & \\
Class 2 & Macao & & & \\
Class 3 & Guangzhou & Shenzhen & & \\
Class 4 & Zhuhai & Foshan & Dongguan & Zhongshan & Jiangmen \\
Class 5 & Huizhou & Zhaoqing & & & \\
\hline
\end{tabular}

and Shenzhen is better than that of other cities in Guangdong Province. The real estate market development is earlier and the market maturity is higher. The economic and real estate markets of Foshan, Dongguan, Huizhou and Zhongshan are deeply affected by the market spillover from Guangzhou, Shenzhen and Hong Kong and Macao. In recent years, the development of the real estate market is also in a rapid development (Chen, Shen, Xiao, \& Zhang, 2017). The remaining cities: Jiangmen and Zhaoqing have a lower level of economic development than other cities in the bay area, and the real estate market is still in the development stage, with great market potential. In addition, due to the "one country, two systems" policy, Hong Kong, Macao and mainland cities have different administrative systems and legal systems, how to promote the sustainable development of the real estate economy of the " $9+2$ " cities in Guangdong-Hong Kong-Macao Greater Bay Area is also a key issue. Based on the different development degree of each market, it is difficult to form corresponding measures to develop and develop the real estate in the bay area Market. Therefore, it also puts forward higher requirements for the comprehensive strength of the real estate enterprises in the bay area.

\subsubsection{The Function of Real Estate Is Single, and It Has Not Developed to a High Level}

In recent years, the development of the real estate market has gradually stepped 
into the mature stage, and the main format of real estate development is housing construction. The real estate development in Hong Kong and Macao analyzed above is the largest. The real estate development in these two regions attaches great importance to its development and utilization as a service function, focusing on the development of real estate to create conditions for its tourism industry, such as Hong Kong Disneyland, which has also played a huge role in driving the relevant industries.

\subsubsection{Waste of Land Resources and Unreasonable Development}

In the Pearl River Delta region, as of 2018, the land development intensity of Shenzhen and Dongguan has far exceeded 45\%, that of Zhuhai and Foshan is about 35\%, and that of Zhongshan and Guangzhou is about 30\%. According to international practice, it is generally considered that a region or city whose land development intensity exceeds $30 \%$ is regarded as unfit for living, which will affect the sustainable development of urban economy and the development of quality of life. Therefore, in the face of land resources and economic and social development at the same time need to solve the problem, we must change the development model, timely make strategic adjustments, adjust management thinking. In the process of real estate development, we should not limit ourselves to the development of commercial housing. For those who develop the tertiary industry, we should take real estate development as the carrier to better guide a region or city to move towards the direction of efficient development, so as to improve the utilization efficiency of land resources and better guide the development of real estate in the bay area to a high level of innovative industry.

\subsubsection{There Is a Shortage of Professional Management Talent}

There is a lack of professional management talents in the bay area, and there is no mechanism to retain talents, which will limit the sustainable development of real estate enterprises. The lack of management talents is a big obstacle to the development of real estate enterprises. In addition, the real estate industry in Guangdong, Hong Kong, Macao and bay area started late, and there is a lack of relevant professional talents, and there is a large demand gap for innovative talents.

\subsection{Opportunities}

The construction of Guangdong-Hong Kong-Macao Greater Bay Area has become China's development strategy, which is not only in line with the actual needs of China's economic and social development, but also the need of national peaceful reunification. In the report of the 19th National Congress of the Communist Party of China, it is proposed that "we should comprehensively promote the mutually beneficial cooperation between the mainland, Hong Kong and Macao, focusing on the construction of the Guangdong-Hong Kong-Macao Greater Bay Area". "seize the major opportunities for the construction of the Guangdong-Hong Kong-Macao Greater Bay Area, enhance the core growth en- 
gine function", and seize the great opportunities for the construction of the Guangdong-Hong Kong-Macao Greater Bay Area (Wang, Wang, \& Li, 2017). point that the construction of the Hong Kong-Zhuhai-Macao Bridge marks the emergence of a new engine for the construction and development of the bay area. At the national level, the local government level, the theoretical level and the practical level, the current development of Guangdong-Hong Kong-Macao Greater Bay Area can be said to be able to get unprecedented development opportunities.

The first half of this article also mentioned that in recent years, many real estate enterprises have settled in the bay area. According to Table 3, we can see that the resident population and GDP in the bay area are at a very high level, which is also a favorable condition for the development of real estate economy in the Bay area. The layout of the leading real estate enterprises reflects the future development prospect of the real estate economy in the bay area from the practical level. Under the overall planning of the bay area, the development of the real estate industry is not limited to residential development. In recent years, the national consumption of tourism, entertainment, culture, education and other aspects is also increasing. In particular, in Guangdong-Hong Kong-Macao Greater Bay Area, the per capita GDP in 2018 has exceeded \$20,000, which has reached the level of developed economies in the upper middle level. Therefore, the pursuit of a high level of life is becoming increasingly fierce, which puts forward higher level requirements for the real estate development mode and innovation in the bay area.

In addition, the economic development level of some cities in the bay area is relatively fast, especially in Hong Kong, Macao, Shenzhen, Guangzhou and other places, the real estate economic development has been relatively mature stage. In the new economic growth point, how to use modern science and technology and innovative technology to innovate the development mode of real estate is very important to meet the development needs of the times.

\section{Development Countermeasures}

Guangdong-Hong Kong-Macao Greater Bay Area is a national development strategy. The development of real estate is an important foundation of urban economic development and the guarantee of people's life. Therefore, it is of great significance to study the development status and Prospect of real estate in Guangdong, Hong Kong, Macao and bay area for its development status, problems and future development direction.

\subsection{Improve the Level of Real Estate Development, Focus on the Direction of High-Quality Development}

With the completion of the Hong Kong-Zhuhai-Macao Bridge and the opening of major traffic arteries such as Shenzhen-Zhongshan Bridge, Nansha Bridge and Shenzhen-Maoming high-speed railway, the ties between Hong Kong, Ma- 
cao and cities on both sides of the Pearl River have been strengthened, and the cities in the bay area can be contacted more comprehensively in space, and information, resources and population will flow more freely. The development of real estate economy in the bay area is not only to develop commercial housing, but also to pay attention to the new needs of consumers and innovation. In the cities with good development potential, we should strengthen the integration of resources in these cities, inject real estate economy into different cities, and make the real estate economy move towards the direction of green, innovation and high level.

\subsection{Comply with the Needs of Cities with Different Levels of Development}

First of all, the government can actively play the role of the real estate enterprises in the bay area. On the basis of the competition and cooperation among the various real estate enterprises in the bay area, the real estate enterprises should be more accurately positioned in the real estate development strategies of different cities from the practical level, and at the same time, they should pay attention to the needs of high-level development. For example, in Hong Kong, on the basis of its mature real estate market, how to combine its real estate development with modern technology and green development concept. In the reality that the market is mature, how to make Hong Kong's real estate move forward to a higher level, and how to promote the real estate economy of Hong Kong to connect with the mainland cities in a practical way, so as to achieve a win-win situation is very crucial. For example, in Macao, there is an imbalance in infrastructure development in some areas. However, after the completion of the Hong Kong-Zhuhai-Macao Bridge, it will be very beneficial for the connection between Macao and the mainland. All real estate enterprises can design relevant schemes to promote the new development of Macao's real estate.

\subsection{Improve the Housing and High-Level Real Estate Construction in the Bay Area}

Gathering management talents provides a higher level of infrastructure for the comprehensive development of the bay area and makes the development of real estate economy develop to a high level. The development of real estate in the bay area started late, and there is a large demand gap for management talents, and there is a lack of innovative talents. If the government wants to broaden the sustainable development of other real estate industries in the bay area, it should actively introduce technology and relevant talents and management experience. In terms of specific talent training scheme, in addition to strengthening the cultivation of senior talents in Guangdong, uniting with universities in Guangdong to form a regional alliance for transporting professional talents, it can also actively promote talent attraction and welfare policies implementation. The introduction of senior talents in real estate management to Guangdong-Hong Kong-Macao Greater Bay Area is more conducive to win-win cooperation between regions, 
and truly moves forward the real estate development towards sustainable, green and high added value.

\section{Conclusion and Limitation of Research}

\subsection{Conclusion}

There are differences in the development of real estate economy in Guangdong, Hong Kong and Macao. Hong Kong and Macao are the regions with the fastest development of real estate economy. However, the development orientation of Hong Kong and Macao is quite different. Hong Kong's leading industry is the development of financial industry, so the rapid development of real estate economy benefits from the continuous increase of its commercial buildings. The real estate industry and the construction industry complement each other. So the continuous development of the real estate industry drives the development of the construction industry. Macao's main economic pillar industry is tourism, which is driven by the vigorous development of hotel construction. In Guangdong, the area of each city is larger than that of Hong Kong and Macao, and the population density is naturally much smaller than that of Hong Kong and Macao. This is also an important reason why the housing prices in Guangdong are not as high as those in Hong Kong and Macao. Although the real estate economic development level of each city in Guangdong is not as high as that of Hong Kong and Macao, in recent years, the real estate economic market development of some cities, especially Guangzhou, Shenzhen, Zhuhai and other places, shows a sustained growth trend. In the bay area of Guangdong, the development of real estate economy also has a big difference. Guangzhou and Shenzhen are far more developed than other cities, and gradually formed urban agglomerations with Guangzhou and Shenzhen as the core. At the same time, in the context of rapid economic development, the ability of Guangzhou and Shenzhen to attract talents is also increasing, attracting a large number of migrant workers and entrepreneurship, which will further stimulate the vigorous development of the real estate economy in the bay area. Dongguan, Zhuhai, Foshan and other cities have relatively rapid development of real estate economy. Because these cities are close to Hong Kong, Macao, Guangzhou and Shenzhen, their economic development is affected by the development of these four cities, so the real estate economy develops relatively fast.

\subsection{The Limitation of Research}

The author is limited by the knowledge skill reserve and time. The research method used in the study has certain limitations. Therefore, there are still some areas where the research is not thoroughly studied, as follows:

1) Due to the limitation of data, the selection and design of indicators has not been further classified scientifically and concretely to study the impact on real estate in different cities in the Greater Bay Area.

2) Due to the differences in the system and the particularity of the Hong Kong 
and Macao special administrative region, the three places are different in statistics of relevant indicators. The specific manifestations are that when selecting the indicator data is selected, the selection of the missing data is discarded, and the analysis of the indicator with the least representative and computational error is selected as much as possible. There is a certain error. Therefore, this problem also needs to be improved.

\section{Conflicts of Interest}

The author declares no conflicts of interest regarding the publication of this paper.

\section{References}

Chen, Y., Shen, B., Xiao, X. C., \& Zhang, N. (2017). Guangdong-Hong Kong-Macao Bay Area: A Grand Chess Game under the One Country, Two Systems Framework. China Development Watch, 14, 22-24.

Deng, Z. X. (2017). Guangdong-Hong Kong-Macao Bay Area: The New Engine of Pearl River Delta Development. Guangdong Economy, 5, 32-35.

DTZ. Industry and Real Estate Lead Investment Opportunities in Grand-Baie (2018). Foshan-Delink Guangdong-Hong Kong-Macao Bay Area Forum Held in Guangzhou, Shenzhen and Hong Kong. Housing and Real Estate, 32, 79-80.

Michael, P. (2002). National Competitive Advantage (pp. 152-155). Beijing: Huaxia Press.

Peng, L. F. (2018). SWOT Analysis of Guangdong-Hong Kong-Macao Bay Area Bidding for 2032 Summer Olympic Games. Journal of Nanjing Institute of Physical Education, 3, 63-70

Wang, J. T. (2017). Enlightenment of the Experience of International Bay Area on the Construction of Guangdong-Hong Kong-Macao Bay Area. Economist, 11, 16-18+20.

Wang, S. (2018). Guangdong-Hong Kong-Macao Bay Area Provides Continuous Impetus for Real Estate Development. China Real Estate, 23, 37-42.

Wang, Z., Wang, C. W., \& Li, H. J. (2017). Strategic Considerations on the Development of the Guangdong-Hong Kong-Macao Bay Area. Guide to China Business and economics, 30, 55-57.

Wei, Y. (2006). Study on the Measurement of Real Estate Market Development Difference between Hong Kong, Macao and Guangdong. Guangzhou: Jinan University. 